\title{
Monitoren en evalueren van integraal gezondheidsbeleid
}

\author{
Een practice-based verkenning
}

Ilse Storm, Marije van Koperen, Fons van der Lucht, Hans van Oers en Jantine Schuit

\author{
Aanbevolen citeerwijze bij dit artikel \\ Ilse Storm, Marije van Koperen, Fons van der Lucht e.a. , 'Monitoren en evalueren van integraal \\ gezondheidsbeleid', Beleidsonderzoek Online september 2014, DOI: 10.5553/Beleidsonderzoek.000043
}

\section{Inleiding}

In Nederland is de afgelopen jaren door onderzoeksgroepen veel kennis gegenereerd over kenmerken die een rol spelen bij de opzet en uitvoering van integraal gezondheidsbeleid (IGB).[1] Echter, IGB kent in de lokale praktijk diverse verschijningsvormen waardoor het lastig is grip te krijgen op de voortgang hiervan. In meest brede zin is IGB beleid waarbij relevante sectoren binnen en buiten het volksgezondheidsdomein werken aan het bevorderen of beschermen van de gezondheid.[2,3] Dat betekent dat het beleid en bijbehorende activiteiten zich niet alleen richten op het individu, maar ook op zijn of haar omgeving (fysiek en sociaal).[2] IGB kan ook specifieker zijn, bijvoorbeeld wanneer de sector volksgezondheid invloed probeert uit te oefenen op beleid van andere sectoren ten behoeve van gezond beleid of wanneer samenwerking met bedrijven of instellingen tot stand komt.[2, 4] De verschijningsvormen van IGB variëren dus in intensiteit, maar ook in aanpak en bijbehorende kenmerken.[5]

IGB wordt vooral gestimuleerd in het kader van complexe gezondheidsproblemen, zoals overgewicht en gezondheidsachterstanden.[2, 3, 6, 7] In Nederland wordt ook steeds meer aandacht besteed aan het ontwikkelen en uitvoeren van IGB.[3, 6, 8] Gemeenten zijn volgens de Wet publieke gezondheid (Wpg) zelfs verplicht om IGB uit te voeren.[8] Om het draagvlak op lokaal niveau voor deze beleidsvorm verder te vergroten en de uitvoering te optimaliseren is het van belang te laten zien dat IGB effectief is in de aanpak van complexe problemen. $[1,9,10]$ Door de diverse verschijningsvormen, maar ook door het ontbreken van eenduidige terminologie en kaders is het niet altijd duidelijk waar het precies om gaat in de Nederlandse IGB-praktijk.[11, 12] Dat maakt het monitoren en evalueren van IGB lastig. De lokale praktijk vraagt wel dringend om een praktisch instrumentarium op dit gebied voor meer zicht en grip op de voortgang van IGB. $[1,13]$

In dit artikel beschrijven we de geleerde lessen in de lokale IGB-praktijk om richting te geven aan monitoring en evaluatie van IGB (een practice-based verkenning). Het doel is om (1) kenmerken van IGB te identificeren op basis van ervaringen in de Nederlandse IGB-praktijk en deze logisch te ordenen, én om (2) praktische instrumenten te identificeren voor het systematisch kunnen monitoren en evalueren van deze kenmerken.

\section{Methode}

\section{Kennissynthese IGB-onderzoeken}

Om een overzicht te krijgen van mogelijkheden om IGB te monitoren of te evalueren in de lokale praktijk is een kennissynthese uitgevoerd. In deze synthese zijn Nederlandstalige kernpublicaties over IGB, welke zijn gepubliceerd tussen 2008-2013, bij elkaar gebracht en bestudeerd. In deze kernpublicaties zijn diverse afgeronde en lopende IGB-onderzoeken in Nederland al op een samenvattende manier beschreven (onder andere door RIVM en RVZ). Vanaf 2008 is meer structureel onderzoek gedaan naar lokaal IGB doordat het belang van deze beleidsvorm steeds meer werd benadrukt, zoals in de landelijke nota's ‘Gezond zijn, gezond blijven' [14] uit 2007 en 'Naar een weerbare samenleving. Beleidsplan aanpak gezondheidsverschillen op basis van sociaaleconomische achtergronden' [15] uit 2008. Afgeronde IGB-onderzoeken op lokaal niveau zijn bijvoorbeeld een 
onderzoek door het RIVM onder 16 gemeenten en een onderzoek door Academische Werkplaats Publieke Gezondheid Limburg onder 19 gemeenten naar het ontwikkelen en uitvoeren van IGB tussen sectoren op gemeentelijk niveau.[16, 17] Van lopende onderzoeken zijn ook nog algemeen beschikbare documenten bekeken, zoals 'Local 50' (evaluatie van het programma Gezonde Slagkracht) en CIAO (Consortium Integrale Aanpak van Overgewicht).

\section{Gebruik van logisch model}

Voor een adequate monitoring en evaluatie is het van belang te verkennen welke kenmerken een rol spelen in de IGB-praktijk, maar ook welke praktische instrumenten daarop kunnen aansluiten. Om de geïdentificeerde kenmerken van IGB uit de Nederlandse praktijk te beschrijven is een ordeningsmodel voor IGB gemaakt. Een dergelijk model komt overeen met het logische evaluatiemodel van Harris en Harris dat specifiek naar de effectiviteit van Health Impact Assessment (HIA) kijkt.[18] Ook andere logische multi-level modellen zijn mogelijk bruikbaar, zoals Referentiekader Saan en de Haas en het EPODE-model.[19, 20] Het HIA-model lijkt het beste aan te sluiten bij deze practice-based verkenning, met de generieke indeling in context, input (beleid, activiteiten), werkwijze/output (actoren en factor) en outcome (gezondheid, determinanten). De HIA (in het Nederlands: gezondheidseffectschatting) is bovendien een aan IGB gerelateerd onderzoeksterrein. Figuur 1 laat een indeling in drie categorieën zien om IGB te ordenen, te weten context, proces, impact. In dit model wordt het proces onderverdeeld in input en werkwijze. De indeling in de categorieën is ook gebruikt om praktische instrumenten te identificeren.

Figuur 1 Generieke indeling om IGB-kenmerken te categoriseren

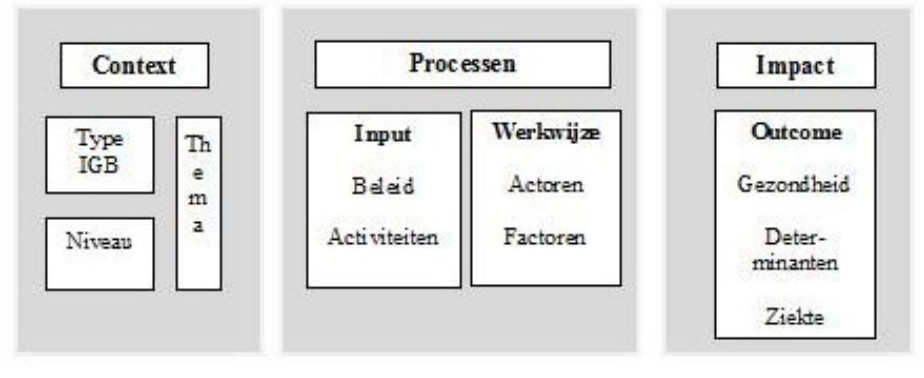

\section{Resultaten}

\section{3a Overzicht geïdentificeerde IGB-kenmerken uit de praktijk}

\section{Verschijningsvormen van IGB: type, niveau en thema}

De synthese van publicaties over IGB-onderzoeken laat zien dat er een grote diversiteit is in type IGB en dat deze beleidsvorm(en) op meerdere niveaus wordt opgezet en uitgevoerd. In het ene geval gaat het om integraal gezondheidsbeleid (in brede zin), dan weer om een integrale aanpak of publiekprivate samenwerking.[2, 17, 21] Ook is sprake van sectoraal beleid dat van invloed kan zijn op gezondheid, waarbij niet altijd een expliciete samenwerking is met de volksgezondheid. Denk bijvoorbeeld aan het terugdringen van taal- en ontwikkelachterstanden in lokaal onderwijsbeleid dat van invloed kan zijn op gezondheidsachterstanden. Tabel 1 geeft een overzicht van de verschillende mogelijkheden. Termen worden in deze publicaties door elkaar heen gebruikt en lijken inwisselbaar. Ook internationaal zijn er verschillende termen en definities in omloop van het vergelijkbare Health in All Policies.[4, 22, 23] Een veelgebruikte definitie is: 'HiAP is a horizontal complementary policyrelated strategy with a high potential for contributing to population health'.[24] Kickbusch maakt daarbij weer onderscheid in drie vormen van IGB oplopend wat betreft intensiteit: Intersectoral Action (IA), Healthy Public Policy (HPP) en Health in All Policies (HiAP).[5] In theorie zijn deze termen en definities nog wel te onderscheiden, maar de lokale praktijk is grilliger en er worden diverse aanpakken en samenwerkingsvormen onder de noemer IGB geschaard. De insteek van IGB wordt ook sterk bepaald door de gekozen thema's of aan te pakken problemen.[7] Thema's in de Nederlandse praktijk van IGB op lokaal niveau zijn vooral gezondheidsthema's (zoals overgewicht en gezondheidsachterstanden) of leefstijlthema's (zoals bewegen, roken en alcohol).[6, 25] Relevante kenmerken voor de context zijn dan onder andere zicht op type IGB (variërend in intensiteit en aanpak), niveau van implementatie (lokaal of regionaal) c.q. setting (wijk, school en werk) en de gekozen thema's (complexe problemen).

\section{Voorbeelden van IGB-terminologie in Nederland}




\begin{tabular}{|l|l|} 
Voorbeelden van IGB invullingen & term \\
\hline $\begin{array}{l}\text { Beleid binnen het volksgezondheidsdomein (VGZ), waarbij samenwerken } \\
\text { mogelijk is tussen een of meerdere sectoren binnen het VGZ-domein }\end{array}$ & Gezondheidsbeleid \\
\hline $\begin{array}{l}\text { Samenwerking tussen meerdere beleidssectoren binnen en buiten het } \\
\text { VGZ-domein rond een volksgezondheidsprobleem }\end{array}$ & $\begin{array}{l}\text { Integraal } \\
\text { gezondheidsbeleid }\end{array}$ \\
\hline $\begin{array}{l}\text { Samenwerking tussen twee beleidssectoren binnen en buiten het VGZ- } \\
\text { domein rond een volksgezondheidsprobleem }\end{array}$ & $\begin{array}{l}\text { Intersectoraal } \\
\text { gezondheidsbeleid }\end{array}$ \\
\hline $\begin{array}{l}\text { Werkwijze waarbij een volksgezondheidsprobleem met meerdere partijen } \\
\text { wordt aangepakt binnen diverse settings (school, wijk, zorg) }\end{array}$ & Integrale aanpak \\
\hline $\begin{array}{l}\text { Samenwerking tussen beleidssectoren en verschillende externe partijen; } \\
\text { deze partijen kunnen ook andere publieke en/of private partijen zijn }\end{array}$ & $\begin{array}{l}\text { Publiek-private } \\
\text { samenwerking }\end{array}$ \\
\hline $\begin{array}{l}\text { Samenwerking tussen meerdere beleidssectoren aan een } \\
\text { gemeenschappelijk doel (maar gezondheid is geen hoofddoel) }\end{array}$ & Integraal beleid \\
\hline $\begin{array}{l}\text { Beleid buiten het VGZ-domein met mogelijke effecten op gezondheid, } \\
\text { maar waarbij geen samenwerking is met het VGZ-domein }\end{array}$ & Sectoraal beleid \\
\hline
\end{tabular}

\section{Beleid en activiteiten in de praktijk}

Naast diversiteit in type IGB en niveaus spelen het gekozen beleid en de activiteiten een rol. Beleid en activiteiten hangen uiteraard nauw samen met de gekozen thema's of aan te pakken problemen. Uit afgeronde onderzoeken binnen gemeenten valt ten eerste op dat het vaker gaat om integrale uitvoering dan om integrale beleidsvorming.[1] Dat betekent dat maatregelen en interventies die worden uitgevoerd binnen projecten op lokaal niveau, zoals in een wijk of school, vooral geïnitieerd zijn vanuit het volksgezondheidsdomein. Bij sociale of gezondheidsprogramma's is wel vaker sprake van integrale beleidsvorming met meerdere sectoren, doordat er integraal wordt gewerkt aan een breed thema (zoals Gezonde Stad).[16, 26] Ten tweede zijn de samenwerkende actoren vaak gezondheids- en welzijnsorganisaties. Over het algemeen geldt op gemeentelijk niveau dat de sociale sectoren (sport, sociale zaken) vaker samenwerken met volksgezondheid dan de fysieke sectoren (ruimtelijke ordening, wonen).[16] Ten derde worden maatregelen en interventies in relatie tot IGB vaak uitgevoerd om gezondheid te bevorderen en minder om te beschermen.[16] Dat betekent dat bij IGB de nadruk vaker op het individu dan op de omgeving ligt om gezond gedrag en gezondheid van burgers te beïnvloeden. $[1,26]$

Relevante proceskenmerken bij beleid en activiteiten zijn dan onder andere aansluiten bij overkoepelende thema's, verbinden van beleid ten behoeve van integrale beleidsvorming en het aanbieden van een interventiemix (zowel gericht op individu als omgeving).

\section{Actoren en factoren in de praktijk}

Naast beleid en activiteiten spelen ook actoren en factoren een rol.[17, 27, 28] Onderzoeken naar IGB laten zien dat binnen de gemeentelijke organisatie met veel verschillende sectoren wordt samengewerkt, zoals ruimtelijke ordening, sociale zaken, onderwijs.[2, 21] Er zijn immers raakvlakken tussen gezondheid en de inrichting van de omgeving, werkgelegenheid, onderwijs, et cetera. Ook kunnen op lokaal niveau veel externe partijen betrokken worden, zoals scholen, woningbouwcorporaties, bedrijven, en ook steeds vaker burgers.[29] Een voorbeeld hiervan is de 'integrale gezonde wijkaanpak', waarin wordt samengewerkt met verschillende actoren aan onder andere leefstijl, wonen, leren en werken.[30] Binnen gemeenten vervullen beleidsambtenaren regelmatig verschillende rollen, zoals makelaar, regisseur, adviseur, aanjager en bewaker.[1] Meestal is er sprake van een regierol in verband met hun wettelijke taak op het gebied van de Wpg. Echter, menskracht en tijd zijn niet altijd in voldoende mate aanwezig. Uit het onderzoek van Steenbakkers blijkt dat managers vrijwel niet betrokken zijn bij IGB. $[1,3]$ Dat betekent dat gezondheid niet altijd centraal staat en de strikte definitie van IGB (waarin gezondheid het gemeenschappelijke doel is) in dit geval niet van toepassing is. Een ander belangrijk aspect is het verankeren van IGB in de gemeentelijke organisatie.[32] In de gezonde slagkracht gemeenten, waar geëxperimenteerd is met IGB, wordt nu vooral ingezet op borging.[32]

Relevante proceskenmerken bij actoren en factoren zijn dan respectievelijk betrokkenheid van gemeentelijke sectoren en private partijen dan wel aanwezigheid van draagvlak, menskracht en verankering in de organisatie.

\section{Gezondheid en determinanten}


De verkenning laat zien dat het bij IGB vaak om een palet van maatregelen gaat dat zowel gericht is op de burger als zijn omgeving. Door de complexiteit is er geen lineaire causaliteit, en is het lastig om te bepalen wat welk effect heeft gehad op gezondheid.[10, 33] In meerdere publicaties is gerapporteerd over onderzoek naar effecten van afzonderlijke lokale beleidsmaatregelen buiten het volksgezondheidsdomein op gezondheid. Er zijn dan vooral effecten te vinden op determinanten van gezondheid (zoals bewegen of luchtkwaliteit), maar meestal is er geen bewijslast op het verbeteren van gezondheid of het terugdringen van gezondheidsachterstanden. Dat komt doordat deze effecten niet zijn onderzocht of de informatie over effecten inconsistent is.[7, 33] Ook zijn er in beperkte mate gezondheidseffecten van community-based interventies in kaart gebracht (zoals Gezond Gewicht Overvecht).[30] Aan het vaststellen van effecten worden vaak ook nog hoge eisen gesteld, zoals uitgaan van bewezen gezondheidseffecten aan de hand van reviews of RCT's. Relevante kenmerken bij impact is onderscheid in outcome oftewel effecten op gezondheid, determinanten en ziekte.

\section{3b Praktische handvatten voor monitoring en evaluatie van IGB}

\section{Passende praktische instrumenten}

Het voorgaande benadrukt dat de diverse verschijningsvormen, wijzen van aanpakken en kenmerken het lastig maken IGB op lokaal niveau te monitoren en te evalueren. Om praktische handvatten te bieden voor monitoring en evaluatie van IGB hebben we bestudeerd wat op dit moment haalbaar is in de Nederlandse praktijk. Daarbij is uitgegaan van de indeling naar context, processen en impact uit het logische evaluatiemodel. Door onderscheid te maken in deze categorieën is het gemakkelijker IGB te omvatten en in hapklare blokken te gaan monitoren en te evalueren.

Context:

Ten aanzien van de context is het mogelijk zinvol een meetlat te ontwikkelen om continuüm van invullingen te bepalen, en zover bekend nog niet beschikbaar. Dit om te monitoren of het bijvoorbeeld gaat om integrale aanpak, gezond beleid of IGB, waarbij de indeling van Kickbusch mogelijk aangrijpingspunten biedt.[5] IGB is dan oplopend wat betreft intensiteit, te weten Intersectoral Action, Health Public Policy en Health in All Policies.[5] De diversiteit aan termen en invullingen van IGB leidt momenteel nog steeds tot verwarring in beleid, onderzoek en praktijk.[1]

Processen:

Op basis van beschikbare kennis en ervaringen over IGB lijkt het momenteel vooral haalbaar gemeenten te ondersteunen met het systematisch inzichtelijk maken van IGB-processen. Dat betekent het genereren van kennis over relevant beleid, activiteiten, actoren en factoren in relatie met IGB. Het is ook wenselijk relevante processen in samenhang te monitoren en te evalueren, omdat dergelijke processen nauw met elkaar samenhangen. Een voorbeeld van een praktisch instrument dat is beschreven door Storm en Meijer, is het spinnenwebmodel IGB.[12]

Voor het spinnenwebmodel zijn twaalf relevante processen (IGB-elementen) geselecteerd.[12] De IGBelementen die staan beschreven in tabel 2, zijn processen die vaak als succesvol naar voren zijn gekomen in de Nederlandse praktijk van IGB.[12] Deze elementen zijn ook terug te leiden naar de processen in het gebruikte logische evaluatiemodel en te gebruiken voor het monitoren van procesmatige aspecten. In figuur 2 zijn de twaalf IGB-elementen visueel weergegeven in een spinnenwebmodel. Dit kan een bruikbaar instrument zijn om IGB-processen in samenhang te presenteren ofwel om de status van integraal werken op lokaal niveau te onderzoeken. Zo biedt het de mogelijkheid om op een schaal van 1 tot 5 eenvoudig te overzien welke elementen 'laag' (1) en welke 'hoog' (5) scoren.[12] Dit genereert kennis om beleidsmakers te ondersteunen in welke processen te investeren en die te gebruiken is als input op strategisch (portefeuillehouders) of tactisch (managers) niveau.[3, 12] Daarmee kan het ondersteuning bieden in de ontwikkeling van IGB en het optimaliseren van deze beleidsvorm. Zo kan de discussie worden aangegaan over de vraag waar de behoeften liggen en wat nodig is voor een betere uitvoering van IGB, waarbij het wenselijk is om op al de twaalf elementen optimaal in te zetten. Ook is het te gebruiken voor monitoring om de ontwikkelingen in de tijd te volgen. Het spinnenwebmodel is getoetst bij een aantal integrale programma's om de meetbaarheid van dergelijke elementen te beoordelen. Het gaat hier om gezondheidsprogramma's die worden aangeduid als integrale initiatieven, zoals Jongeren op Gezond Gewicht (JOGG), lokaal actief, gezonde stad.

Impact:

Ten aanzien van de impact is het duidelijk dat het nog te complex is om een pakket aan maatregelen te beoordelen op gezondheidseffecten (vooral niet op korte termijn). Het lijkt wel haalbaar om naar determinanten te kijken van gezondheid, maar dan van afzonderlijke maatregelen op deze determinanten. Een voorbeeld is het gebruik van een doelenboom, welke is gepresenteerd in de VTV2010. Een dergelijke boom houdt rekening met de gelaagdheid van doelen, zoals gezondheid, 
determinanten, gezondheidsproblemen en ziekte, en biedt mogelijk aangrijpingspunten voor het monitoren en evalueren van effecten.[34] Voor zover bekend zijn dergelijke instrumenten specifiek voor IGB (nog) niet beschikbaar.

2 Relevante IGB-elementen naar proces

\begin{tabular}{|c|c|c|}
\hline & IGB-elementen & Beschrijving \\
\hline 1 & $\begin{array}{l}\text { Bestuurlijk en } \\
\text { politiek draagvlak }\end{array}$ & $\begin{array}{l}\text { Voldoende draagvlak op bestuurlijk niveau (managementsteun) en } \\
\text { politiek niveau (agendasetting) }\end{array}$ \\
\hline 2 & $\begin{array}{l}\text { Samenwerken } \\
\text { met } \\
\text { gemeentelijke } \\
\text { sectoren }\end{array}$ & $\begin{array}{l}\text { Het vormen van netwerken en het onderhouden hiervan (met name } \\
\text { fysieke sectoren) }\end{array}$ \\
\hline 3 & $\begin{array}{l}\text { Samenwerken } \\
\text { met publiek- } \\
\text { private partijen }\end{array}$ & $\begin{array}{l}\text { Inzetten op samenwerking met bedrijven, zorgverzekeraars, } \\
\text { woningbouwcorporaties, etc. }\end{array}$ \\
\hline 4 & Sociale marketing & $\begin{array}{l}\text { Gebruikmaken van sociale marketing principes (aansluiten bij burgers } \\
\text { en partners/bestuurders) }\end{array}$ \\
\hline 5 & $\begin{array}{l}\text { Probleemeigenaar } \\
\text { en menskracht }\end{array}$ & $\begin{array}{l}\text { Benoemen van een probleemeigenaar (regie) en beschikbaar stellen } \\
\text { van menskracht }\end{array}$ \\
\hline 6 & $\begin{array}{l}\text { Visie en cultuur } \\
\text { op integraal } \\
\text { werken }\end{array}$ & $\begin{array}{l}\text { Gezamenlijke visie en cultuur op integraal werken om gezondheid te } \\
\text { bevorderen en/of te beschermen }\end{array}$ \\
\hline 7 & $\begin{array}{l}\text { Verankering IGB } \\
\text { in organisatie }\end{array}$ & $\begin{array}{l}\text { Inzetten van structurele organisatiestructuren en beleidsprocessen en } \\
\text { financiën voor IGB }\end{array}$ \\
\hline 8 & $\begin{array}{l}\text { Gebruik van } \\
\text { kennis en } \\
\text { methoden }\end{array}$ & $\begin{array}{l}\text { Inhoud kiezen over in te zetten (mix) aan effectieve activiteiten en } \\
\text { gebruik ondersteunende methoden }\end{array}$ \\
\hline 9 & $\begin{array}{l}\text { Concrete } \\
\text { gezondheids- } \\
\text { doelstellingen }\end{array}$ & $\begin{array}{l}\text { Formuleren concrete doelstellingen op gezondheid en determinanten } \\
\text { van gezondheid (in nota's) }\end{array}$ \\
\hline 10 & $\begin{array}{l}\text { Aansluiten op } \\
\text { gemeentelijke } \\
\text { thema's }\end{array}$ & $\begin{array}{l}\text { Aansluiten gemeenten met gezondheid op overkoepelende } \\
\text { gemeentelijke thema's }\end{array}$ \\
\hline 11 & $\begin{array}{l}\text { Verbinden van } \\
\text { beleid }\end{array}$ & $\begin{array}{l}\text { Benoemen wat andere sectoren al doen op het gebied van gezondheid } \\
\text { (en bijbehorende determinanten) en inzichtelijk maken wat } \\
\text { gezondheid voor andere sectoren kan betekenen (als middel) }\end{array}$ \\
\hline 12 & $\begin{array}{l}\text { Activiteiten in } \\
\text { samenhang } \\
\text { implementeren }\end{array}$ & $\begin{array}{l}\text { In samenhang en gecoördineerd inzetten van activiteiten } \\
\text { (interventiemix) }\end{array}$ \\
\hline
\end{tabular}

Figuur 2: Spinnenwebmodel voor IGB-processen (met een fictief voorbeeld) [12] 


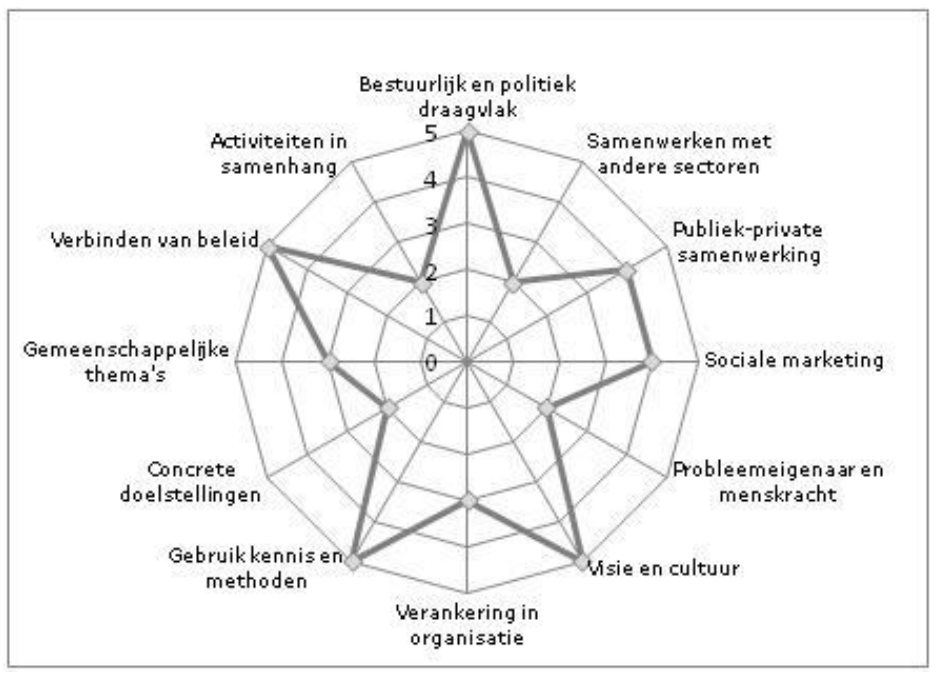

\section{Discussie}

\section{Monitoren IGB-processen meest haalbaar}

Door de verschillende verschijningsvormen en kenmerken van IGB, en het ontbreken van eenduidige terminologie blijkt het lastig dit beleid te monitoren en evalueren. In de kennissynthese van Nederlandse kernpublicaties over IGB is gekeken wat op basis van de ervaringen in de IGB-praktijk tot nu toe gezegd kan worden over het monitoren en evalueren van IGB. Bij deze practice-based verkenning naar IGB-kenmerken en bijbehorende praktische instrumenten is gebruikgemaakt van een indeling in drie categorieën: context, processen en impact.

Uit de verkenning blijkt dat er verschillende IGB-kenmerken te identificeren zijn in zowel de opzet en uitvoering van IGB als monitoring en evaluatie van IGB. Voor de context zijn relevante kenmerken: type IGB, niveau van uitvoering en het gekozen thema. Relevante kenmerken voor processen zijn: vormgeven van beleid (zoals aansluiten overkoepelende thema's en verbinden van beleid), uitvoeren van activiteiten gericht op zowel individu als omgeving (zoals de interventiemix), betrekken van actoren (zoals bestuurders, gemeentelijke sectoren en burgers), en het beïnvloeden van factoren (zoals probleemeigenaar en menskracht, verankering in organisatie en gebruik van kennis). Relevante kenmerken voor impact zijn vaststellen van effecten op gezondheid, determinanten of ziekte. Wat betreft de drie categorieën lijkt het vooral haalbaar de context en procesmaten te monitoren en te evalueren, maar dit is lastiger voor impactmaten. Monitoring en evaluatie van meer procesmatige aspecten wordt bijvoorbeeld ook aanbevolen voor de evaluatie van de vergelijkbare complexe multilevel systeemaanpak van overgewicht.[35] Het monitoren en evalueren van IGB-processen is ook relevant, omdat sectoren elkaar op lokaal niveau steeds meer nodig hebben in maatschappelijke opgaven.[36]

\section{Ontwikkeling van praktische onderzoeksinstrumenten}

De verkenning laat ook zien dat er nog weinig praktische instrumenten zijn om specifiek IGBprocessen in samenhang te monitoren. Het spinnenwebmodel van Storm en Meijer is een voorbeeld van een praktisch instrument om deze processen in samenhang te bekijken. Er is echter nog doorontwikkeling nodig voor het vaststellen van de juiste set van betrouwbare elementen c.q. kenmerken.[12] Zo was er bij het testen van het spinnenwebmodel van Storm en Meijer bij meerdere integrale programma's soms verwarring over de betekenis van enkele IGB-elementen, zoals wat wordt verstaan onder sociale marketing of bestuurlijk en politiek draagvlak. Dit zijn vaak nog abstracte begrippen. Het verder meetbaar maken van dergelijke processen op het juiste abstractieniveau is dan ook wenselijk. Voor sociale marketing en bestuurlijk en politiek draagvlak wordt dat momenteel uitgevoerd door onder andere het Consortium Integrale Aanpak Overgewicht (CIAO).[37] Het blijft dus van belang na te denken over hoe om te gaan met het monitoren en evalueren van IGBprocessen, maar dat geldt ook voor de context en impact. Voor de context liggen praktische handvatten bijvoorbeeld bij het ontwikkelen van een IGB-meetlat, waarbij de indeling van Kickbusch mogelijk ondersteunend kan zijn.[5] Het gebruik van een doelenboom, zoals gebruikt in de VTV-2010, kan mogelijk helpen bij het inzichtelijk maken van gezondheidseffecten.[34] Ook is het voor impactmaten van belang aandacht te hebben voor andere onderzoeksmethoden dan reviews of RCT's [1], zoals (kwantitatief of kwalitatief) observationeel of quasi-experimenteel onderzoek. 
Door de complexiteit en diversiteit van IGB is het van belang te beschikken over meerdere onderzoeksinstrumenten om IGB-kenmerken te monitoren en te evalueren, bijvoorbeeld specifiek gericht op context, procesmaten of impactmaten. Dat wil zeggen dat IGB te omvattend is om in het geheel te onderzoeken en het van belang is om dit op te delen in 'hapklare' blokken. Het spinnenwebmodel lijkt bruikbaar om IGB-processen in samenhang inzichtelijk te maken, maar uiteraard zijn ook andere instrumenten denkbaar. Zo kan het zinvol zijn in te zoomen op een specifiek proces, zoals samenwerken tussen sectoren. In de instrumenten of methoden is dus ook een gelaagdheid voorstelbaar. Bijvoorbeeld: een logisch model is als een instrument te zien (zoals logic model HIA), maar daarbinnen kan een instrument zich richten op het geheel van processen (zoals het spinnenwebmodel), en binnen het onderdeel processen kan een instrument zich weer richten op elementen (zoals samenwerken en netwerken tussen sectoren). Dergelijke instrumenten hebben verschillende doelstellingen en abstractieniveaus. Het is een continu voortschrijdend inzicht dat samenhangt met de dynamiek en complexiteit van IGB, en het werken aan een set met complementaire methoden en instrumenten staat op de onderzoeksagenda.[32]

\section{Theoretisch kader ontbreekt deels}

De verkenning in dit artikel laat ook zien dat er veel kennis is vanuit de Nederlandse praktijk. Wat nog goeddeels ontbreekt, is een theoretische onderbouwing van methoden en instrumenten om lokale IGB-processen en -praktijken te monitoren en te evalueren. Ook voor het meetbaar maken van bijbehorende IGB-kenmerken is dat essentieel. Voor het gebruik van eenduidige termen en begrippen kunnen theoretische kaders ondersteunend zijn. Vanuit de landelijke overheid wordt dit ook herkend, en financiert ZonMw momenteel diverse projecten die toewerken naar het meetbaar maken van diverse kenmerken, zoals het Consortium Integrale Aanpak van Overgewicht (CIAO) en het Consortium instruments for integrated action (i4i).[38] Vanaf september 2012 werken in het consortium i4i negen onderzoeksgroepen in Nederland samen aan lokaal passende onderzoeksinstrumenten voor integraal gezondheidsbeleid (IGB) en samenwerking beleid-onderzoekpraktijk (BOP). Diverse kennisdisciplines (gezondheidswetenschappen, sociologie, psychologie, bestuurskunde, etc.) komen bij elkaar voor meer duiding van IGB en grip op processen en praktijken van IGB. Hierbij wordt ook gebruikgemaakt van relevante IGB-projecten, zoals Local 50, Urban 40, Beweeg je Buurt II, CIAO. In het project i4i worden theoretische concepten ingebracht in de te ontwikkelen onderzoeksinstrumenten voor monitoring en evaluatie. Ook internationaal staat effectiviteit van IGB, onder de term Health in All Policies (HiAP), volop in de aandacht.[9, 39] De ontwikkelde nationale en internationale kennis zal uiteindelijk leiden tot meer inzicht in diverse vormen van IGB en onderscheidende onderdelen c.q. kenmerken, wat ook ten goede komt aan de monitoring en evaluatie ervan op lokaal niveau. Op basis van deze ontwikkelingen zijn passende onderzoeksinstrumenten (door) te ontwikkelen voor ondersteuning van de IGB-praktijk. Daarbij blijft het belangrijk de ervaringen in de praktijk mee te nemen en aan te sluiten bij de bestuurlijke en maatschappelijke realiteit.

\section{Conclusie}

De practice-based verkenning om lokale IGB-praktijken te monitoren en te evalueren laat zien dat het vooral mogelijk is kennis te genereren over context en procesmaten, en minder over impactmaten. Uiteindelijk is het wenselijk tot een set van gevalideerde instrumenten te komen voor monitoring en evaluatie van IGB. Theoretische onderbouwing is dan wel een essentiële voorwaarde.

\section{Literatuur}

Storm, I., Verweij, A., \& Van der Lucht, F. (2011). Integraal gezondheidsbeleid op lokaal niveau. Wat weten we en hoe nu verder? RIVM rapport 270161004. Bilthoven: RIVM.

Storm, I., Van Zoest, F., \& Den Broeder, L. (2007). Integraal gezondheidsbeleid: theorie en toepassing. RIVM rapport 270851003. Bilthoven: RIVM.

Steenbakkers, M. (2012). Lokaal integraal gezondheidsbeleid: realistische uitdaging of utopie? Een onderzoek binnen gemeenten naar mogelijkheden tot intersectorale samenwerking. Academische Werkplaats Publieke Gezondheid Limburg. Maastricht: Universiteit Maastricht.

Stahl, T., Wismar, M., Ollila, E., Lathinen, E., \& Leppo, K. E. (2006). Health in all policies: Prospects and potentials. Helsinki: Finnish Ministry of Social Affairs and Health, European Observatory on Health Systems and Policies.

Kickbusch, I., \& Gleicher, D. (2011). Governance for health in the 21st century: a study conducted for 
the WHO Regional Office for Europe. Copenhagen: WHO Regional Office for Europe.

Van der Lucht, F., \& Polder, J. J. (2010). Van gezond naar beter. Volksgezondheid Toekomst Verkenning 2010. Houten: Bohn Stafleu Van Loghum.

Schrijvers, C. T. M., \& Storm, I. (2009). Naar een integrale aanpak van gezondheidsachterstanden. Een beschrijving van beleidsmaatregelen binnen en buiten de volksgezondheidssector. RIVM rapport 270171001. Bilthoven: RIVM.

RVZ. (2009) Buiten de gebaande paden. Advies over intersectoraal gezondheidsbeleid. Zoetermeer: Raad voor de Volksgezondheid en Zorg, de Onderwijsraad en de Raad voor het openbaar bestuur.

St-Pierre, L., Hamel, G., Lapointe, G., Mc Queen, D., \& Wismar, M. (2009). Governance tools and framework for health in all policies. European Observatory on health systems and policies.

Maas, J., \& Storm, I. (2011). Integraal gezondheidsbeleid op nationaal niveau. Wat kunnen we leren van de ervaringen uit andere landen? Bilthoven: RIVM.

Seidell, J., et al. (2010). Eindrapportage Fase I CIAO - Consortium Integrale Actie tegen Overgewicht. Den Haag: ZonMw.

Meijer, S., \& Storm, I. (2012). Integrale inzichten. Een verkenning van vijf lokale integrale gezondheidsprogramma's. Bilthoven: RIVM.

Schuit, J. \& Storm, I. (2007). Successen en valkuilen van integraal gezondheidsbeleid. Tijdschrift voor Gezondheidswetenschappen, 85(8), 415-416.

VWS. (2007). Gezond zijn, gezond blijven. Een visie op gezondheid en preventie. Den Haag: Ministerie van Volksgezondheid, Welzijn en Sport (VWS).

VWS. (2008). Naar een weerbare samenleving. Beleidsplan aanpak gezondheidsverschillen op basis van sociaaleconomische achtergronden. Den Haag: Ministerie van Volksgezondheid, Welzijn en Sport (VWS).

Storm, I., Savelkoul, M., Busch, M. C. M., Maas, J., \& Schuit, A. J. (2010). Intersectoraal samenwerken in de aanpak van gezondheidsachterstanden. Een onderzoek onder zestien gemeenten in Nederland. RIVM rapport 270161002. Bilthoven: RIVM.

Steenbakkers, M., Jansen, M., Maarse, H., \& De Vries, S. (2010). Lokaal integraal gezondheidsbeleid: intersectorale samenwerking vanuit het perspectief van gemeenten .Tijdschrift voor Gezondheidswetenschappen, 88, 13-43.

Harris, B. \& Harris, E. (2013). The impact and effectiveness of Health Impact Assessment: A conceptual framework .Environmental Impact Assessment Review, 42, 51-59.

Van Koperen, T. M., Jebb, S. A., Summerbell, C. D., Visscher, T. L., Romon, M., Borys, J. M., \& Seidell, J. C. (2013). Characterizing the EPODE logic model: unravelling the past and informing the future. International Association for the Study of Obesity. Obesitas reviews.

Saan, H., \& De Haas, W. (2005). Gezond effect bevorderen. Het organiseren van effectieve gezondheidsbevordering. Woerden: NIGZ.

Aarts, M. J., Jeurissen, M. P. J., Van Oers, J. A. M., Schuit, A. J., \& Van der Goor, L. A. M. (2010). Multi-sector policy action to create activity-friendly environments for children: A multiple-case study. Health Policy.

WHO. (2011). Governance for health in the 21st century: a study conducted for the WHO Regional Office for Europe. Copenhagen: World Health Organization Regional Office for Europe.

Bovill, C. (2010). Rhetoric or reality? Cross-sector policy implementation at the UK government Department for International Development. Policy and Politics, 37(2), 179-199.

Puska, P., \& Stahl, T. (2010). Health in all policies - the Finnish initiative: background, principles, and current issues .Annu Rev Public Health, 31, 315-328. 
CGL. (2012). Materialen uit de handreiking. Integraal beleid. Ontleend aan:

http://www.loketgezondleven.nl/settings/gezonde-gemeente/materialen/.

Bekker, M., Steenbakkers, M., Storm, I., \& Jansen, M. (2013). From instruments towards programme for HiAP decision-support? Health Impact Assessment in the Netherlands . In M. O'Mullane et al. (eds). Integrating health impact assessment into the policy process: Lessons and experiences from around the world. Oxford: Oxford University Press.

Bekker, M. (2007). The politics of healthy policies: Redesigning health impact assessment to integrate health in public policy. Delft: Eburon.

Storm, I., Savelkoul, M., Busch, M. C. M., Maas, J., \& Schuit, A. J. (2010). Intersectoraal samenwerken in de aanpak van gezondheidsachterstanden. Een onderzoek onder zestien gemeenten in Nederland. RIVM rapport 270161002. Bilthoven: RIVM.

CGL. (2012). Burgers en doelgroepen. Uit: Handreiking Gezonde Gemeenten. Ontleend aan: http://loketgezondleven.nl/settings/gezonde-gemeente/randvoorwaarden/draagvlak/burgers-endoelgroepen/.

Meijer, S., \& Sturkenboom, M. (2009). Gezond wonen en werken. Een oriëntatie op gezondheidsbevordering in de settings wijk en werk in Nederland. Bilthoven: RIVM.

Steenbakkers, M., Jansen, M., Maarse, H., \& De Vries, N. (2012). Challenging health in all policies, an action research study in Dutch municipalities .Health Policy, 105(2-3), 288-295.

ZonMw. (2013). Resultaten van het ZonMw programma Gezonde Slagkracht. Den Haag: ZonMw.

Savelkoul, M., Schuit, A.J., \& Storm, I. (2010). Terugdringen van gezondheidsachterstanden door gemeentelijk beleid. RIVM rapport 270161003. Bilthoven: RIVM.

Van den Berg, M. \& Schoemaker, C. (2010). Effecten van preventie. Deelrapport van de VTV 2010 Van gezond naar beter. Houten: Bohn Stafleu Van Loghum.

Frerichs, L., Puricelli Perin, D. M., \& Huang, T. T.-K. (2012). Current trends in childhood obesity research. Curr Nutr Rep, 1, 228-238.

VWS. (2013). Alles is gezondheid... Het Nationaal Programma Preventie 2014-2016. Kamerbrief. Den Haag: Ministerie van Volksgezondheid, Welzijn en Sport (VWS).

Van Koperen, T.M., et al. (2014). Design of CIAO, a research program to support the development of an integrated approach to prevent overweight and obesity in The Netherlands . BMC Obesity, 1:5.

ZonMw. (2012). Consortium Instruments for Integrated Action (i4i). Den Haag: ZonMw. Ontleend aan: http://www.zonmw.nl/nl/projecten/project-detail/consortium-instruments-for-integratedaction-i4i/samenvatting/.

Storm, I. (2012). International policy overview: Health in All Policies (HIAP). Bilthoven: RIVM. Ontleend aan:

http://www.nationaalkompas.nl/object_binary/o13534_International\%20Policy\%2oOverview_HiAP_Mei2012.pdf. 